\title{
A Case of Recurrent Anaplastic Meningioma of the Skull Base with Radiologic Response to Hydroxyurea
}

\author{
Joshua Gurberg ${ }^{1}$ Nathaniel Bouganim ${ }^{2}$ George Shenouda ${ }^{3}$ Anthony Zeitouni ${ }^{4}$ \\ ${ }^{1}$ Division of Otolaryngology-Head and Neck Surgery, The University of \\ Address for correspondence Dr. Anthony Zeitouni, MD, MSc, \\ British Columbia, Vancouver, British Columbia, Canada \\ 2 Department of Oncology, McGill University, Montreal, Quebec, \\ Canada \\ Department of Otolaryngology-Head and Neck Surgery, Royal Victoria \\ Hospital, Room E4.45, 687 Pine Avenue West, Montreal, QC, H3A 1A1, \\ Canada (e-mail: Anthony.Zeitouni@mcgill.ca).
}

${ }^{3}$ Department of Radiation Oncology, McGill University, Montreal,

Quebec, Canada

${ }^{4}$ Department of Otolaryngology-Head and Neck Surgery, Royal

Victoria Hospital, McGill University Health Center, Montreal, Quebec,

Canada

J Neurol Surg Rep 2014;75:e52-e55.

\begin{abstract}
Keywords

- meningioma

- anaplastic meningioma

- hydroxyurea

- radiotherapy

- recurrent

- malignant transformation
\end{abstract}

\section{Introduction}

Meningiomas account for 13 to $26 \%$ of intracranial neoplasms. ${ }^{1}$ Of these, 2 to $3 \%$ are anaplastic (World Health Organization [WHO] grade III) as characterized by neoplastic cytologic features and a high mitotic index. ${ }^{2,3}$ These lesions rarely metastasize but commonly recur, especially if they are subtotally excised, located at the skull base, or infiltrate the brain parenchyma. ${ }^{1,4}$ Anaplastic meningiomas carry a particularly poor prognosis, with a median survival time of 1.5 years and a 5 -year mortality of $68 \%{ }^{1}$

received

April 12, 2013

accepted after revision

September 17, 2013

published online

April 17, 2014
The current standard of care for anaplastic meningiomas, at initial presentation, is surgery followed by postoperative fractionated radiotherapy. ${ }^{5}$ For recurrent meningiomas, if the tumor is not surgically accessible and reirradiation is not possible, chemotherapy is then attempted. ${ }^{5}$ Options include cytotoxic agents, hormonal therapy, and targeted agents. ${ }^{2}$ One agent being aggressively pursued is hydroxyurea (HU), a selective inhibitor of ribonucleoside diphosphate reductase, because of its ability to induce apoptosis of meningioma cells in vitro, ease of administration, and acceptable toxicity profile. $^{6,7}$ Thus far, many case series have only shown HU

\footnotetext{
(c) 2014 Georg Thieme Verlag KG Stuttgart · New York
} 
to induce stable disease, with no documented objective radiologic responses. ${ }^{2}$

This article reviews the literature pertaining to the use of HU for anaplastic meningioma and presents a report of the only known case of partial response to HU given after reirradiation for a recurrent anaplastic meningioma of the skull base.

\section{Case Report}

The patient is a 58 year-old female professor who first presented to the Head and Neck clinic in October 2008 with left-sided facial pain, otalgia, and aural fullness. She was a smoker and had a past history of cataract surgery, salpingooophorectomy for severe endometriosis, and left otitis media with effusion requiring pressure equalization tube several months prior. Physical examination revealed a leftsided V2/V3 dysthesia and a left middle ear effusion. Magnetic resonance imaging (MRI) with gadolinium infusion of the base of the skull demonstrated a left $2.8 \times 2.8 \times 3.3 \mathrm{~cm}$ isointense left infratemporal fossa mass involving the left wing of the sphenoid and pterygopalatine fossa, extending through the foramen ovale to involve the meninges of the left middle cranial fossa. Endoscopically guided biopsy using a transnasal and transantral pterygopalatine approach demonstrated a WHO grade I meningioma. The consensus at the tumor board was to recommend treatment with stereotactic fractionated radiotherapy. Instead, the patient sought a second opinion and underwent gamma knife radiosurgery at an outside institution in November 2008, where she received a dose of $12 \mathrm{~Gy}$ in a single fraction with a peripheral dose of 12 Gy covering $98 \%$ of the tumor volume (30.1 cc) with a maximal dose of $24 \mathrm{~Gy}$. The maximal dose to the optic structures did not exceed $4 \mathrm{~Gy}$. She was followed periodically with imaging that revealed interval stability of the residual tumor mass.

In October 2011, the patient returned to the clinic with headache, facial pain, respiratory difficulty, and nasopharyngeal reflux. MRI revealed local recurrence of the tumor invading the left masticator and parapharyngeal spaces and at the skull base with cortical bone invasion of the left mandibular ramus. A metastatic work-up did not demonstrate distant spread. With tumor board consensus, the patient underwent a wide local excision of the mass via a left lateral rhinotomy with a left maxillectomy, left partial palatectomy, and left level I-III neck dissection. Pathology revealed anaplastic (WHO grade III) meningioma with positive surgical margins. She then received adjuvant reirradiation consisting of fractionated stereotactic radiotherapy of $60 \mathrm{~Gy}$ in 30 daily fractions of $2 \mathrm{~Gy}$ each over an overall treatment time of 6 weeks. The treatment was delivered using $6 \mathrm{MV}$ photons on a Novalis linear accelerator and BrainLab planning system. The planning target volume (PTV) consisted of the gross tumor volume with a 3-mm margin. The patient was immobilized using a relocatable mask with daily verification using kv-kv verification. The reirradiation was given with concomitant Temodol $\left(75 \mathrm{mg} / \mathrm{m}^{2}\right.$ daily) ending in March 2012.
Unfortunately, in April 2012 the patient presented to the emergency department with epistaxis, and MRI revealed progression of the mass with increased invasion of the left temporal bone and orbit (-Figs. 1A, 1C). At this point palliative care was consulted, and medical oncology began a palliative course of HU 1800 mg daily by mouth, subsequently reduced to $1500 \mathrm{mg}$ because of grade 3 pancytopenia. Surprisingly, after 5 months of therapy, follow-up MRI in September 2012 demonstrated a significant interval decrease in tumor volume with cavitation of the lesion (-Figs. 1B, 1D). The patient is currently doing well on $1500 \mathrm{mg}$ HU daily.

\section{Discussion}

To our knowledge, this is the first reported case of a WHO grade III meningioma with an objective radiologic response to HU following reirradiation. Several clinical studies of HU have been published including patients with WHO grade III meningiomas (- Table 1). In 1997, Schrell and colleagues evaluated the activity of $\mathrm{HU}(20 \mathrm{mg} / \mathrm{kg} /$ day $)$ in four patients with recurrent unresectable meningiomas. The one patient harboring a WHO grade III tumor had no shrinkage of the tumor but had disease stabilization over 24 months of therapy. ${ }^{8}$ In a similar study, Mason et al evaluated the efficacy of $20-30 \mathrm{mg} /$ $\mathrm{kg} /$ day HU in a cohort of 20 patients over a 2-year treatment period. The one patient with a grade III malignant neoplasm had progressive disease on neuroimaging after 24 weeks of therapy. ${ }^{9}$

Hahn and colleagues evaluated the use of $20 \mathrm{mg} / \mathrm{kg} /$ day HU and concurrent conformational radiation therapy for 12 weeks in 21 patients with recurrent or progressive disease. ${ }^{3}$ The two patients with WHO grade III lesions had no radiologic responses to treatment with a median progression-free survival time of 13 months. ${ }^{3}$ In another modification, Reardon and associates evaluated the effect of $500 \mathrm{mg}$ HU given twice a day along with imatinib 400 to $1000 \mathrm{mg}$ daily. Four patients had grade III lesions, and the best response was stable disease and only $46.2 \%$ progression-free survival at 6 months. ${ }^{10}$

In 2012, Chamberlain published a retrospective case series focusing on high-grade lesions that consisted of 22 patients with WHO grade II and 13 patients with WHO grade III recurrent meningiomas treated with $1000 \mathrm{mg} / \mathrm{m}^{2}$ HU. $^{7}$ There were no radiologic responses. ${ }^{7}$

Thus HU has been used in 21 patients with anaplastic meningioma without a single objective radiologic response (-Table 1). Our patient, like these others, is in her 6th decade of life and had already had disease progression after two courses of radiotherapy, Temodol, and surgery. The dose of HU and dosing schedule were also similar. However, this patient differed from most of the described cases in that she had been previously treated with Temodol chemotherapy and that the time between completing reirradiation and beginning HU was $<1$ month.

One must ask why this patient responded when the other 21 did not. There are several possibilities. Perhaps the number needed to treat with $\mathrm{HU}$ is such that one has not seen the full 


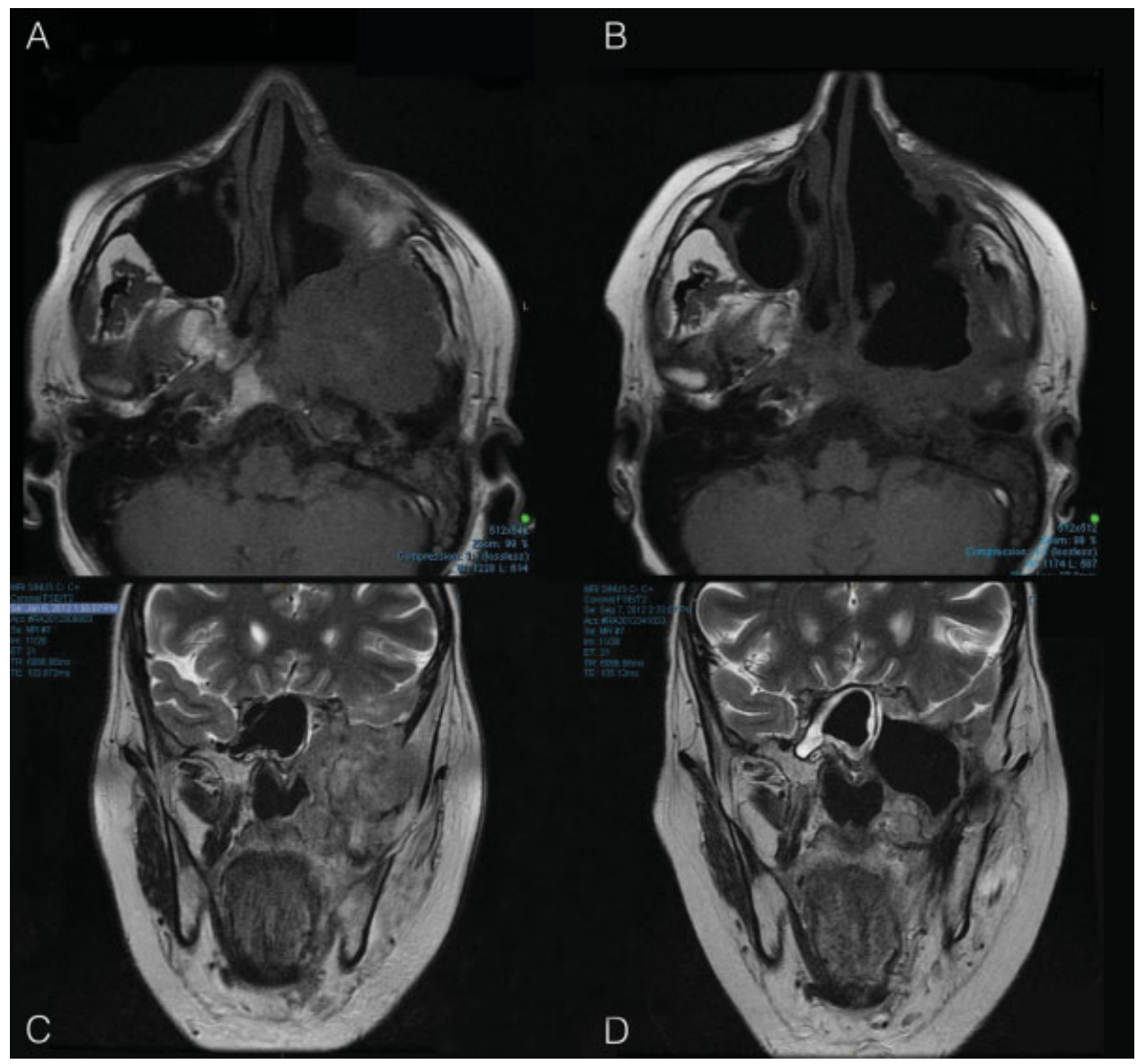

Fig. 1 Magnetic resonance Imaging of the sinuses (A) April 2012 axial, (B) September 2012 axial, (C) April 2012 coronal, (D) September 2012 coronal. Pre- and post-hydroxyurea demonstrating a significant objective radiologic response.

effect of this agent with such a small number of cases. An interaction between $\mathrm{HU}$ and the previously administered Temodol is also possible. More plausible, however, is an interaction between $\mathrm{HU}$ and the stereotactic reirradiation therapy that was given shortly before the drug.

Before discussing the possible interaction between ionizing radiation and $\mathrm{HU}$, the interaction between ionizing radiation (IR) and tumor progression is of interest. Several cases have been reported in the literature describing malignant transformation of meningioma after gamma knife radiosurgery (GKR) ${ }^{11-14}$. In the present case, the patient's meningioma was first classified as WHO grade I in 2008; however, it recurred as WHO grade III disease, 3 years after GKR. This is yet another example of possible progression of benign meningioma secondary to GKR. However, as discussed by Kubo and colleagues in their case series on this topic, the histologic diagnosis of irradiation-induced malignant transformation is extremely challenging, and the relationship may in fact be the result of GKR being used to treat recurrent disease that may have actually transformed prior to irradiation. ${ }^{11}$

In discussing the temporal relationship between $\mathrm{HU}$ and reirradiation of the lesion, it is important to mention that in the Hahn et al study, ${ }^{3}$ concurrent HU and radiotherapy only induced stable disease. There are, however, intriguing reports in the basic science literature of the effects of HU administered closely after ionizing radiation. $\mathrm{HU}$ is an inhibitor of the DNA repair enzyme ribonucleotide reductase (RR). The molecular target of $\mathrm{HU}$ is the tyrosyl radical of the $\mathrm{R}_{2}$ subunit of the RR enzyme. By inhibiting the RR, HU inhibits the conversion of the ribonucleotide phosphates to deoxyribonucleotide forms that are essential for DNA synthesis and repair. Many investigators have studied the temporal relationship of the interaction of HU and IR. In 1997, Kuo and colleagues studied the effect of sequencing of HU exposure before and after IR exposure in human cancer cell lines. The authors reported a larger degree of radiosensitization when HU shortly followed IR as compared with HU delivered before IR. ${ }^{15}$ The proposed mechanism of the observed radiosensitization was that IR induced DNA damage and this induced a subsequent increase in RR activity to perform DNA repair. ${ }^{16}$ When this IR-induced increase in RR activity was shortly followed by the exposure to $\mathrm{HU}$, which is an RR inhibitor, the IR-induced repairable DNA lesions were converted to irreparable DNA lesions with a significant increase in radiosensitization. ${ }^{16}$ Similar results were reported by Ward and associates, who found that HU treatment immediately after IR directly inhibited the IR-induced DNA repair in HeLa cancer cervix cell lines. ${ }^{17}$

Thus we report the first case of a patient with recurrent anaplastic meningioma to have a near complete/partial 
Table 1 Summary of current studies on the efficacy of hydroxyurea in anaplastic (WHO grade III) meningioma

\begin{tabular}{|c|c|c|c|c|c|c|c|c|}
\hline Study & Age, sex & $\begin{array}{l}\text { No. of } \\
\text { patients }\end{array}$ & NOS & $\begin{array}{l}\text { Prior RT } \\
\text { (mo pre-HU) }\end{array}$ & $\begin{array}{l}\text { Prior ChemoRx } \\
\text { (mo pre-HU) }\end{array}$ & $\begin{array}{l}\text { Best } \\
\text { response }\end{array}$ & Follow-up & $\begin{array}{l}\text { Toxicity of } \\
\text { grade } 3 \text { or } \\
\text { higher }\end{array}$ \\
\hline Schrell et $\mathrm{al}^{8}$ & $56, M$ & 1 & 6 & Yes, RT (60) & No & SD & $24 \mathrm{mo}$ & No \\
\hline Mason et $\mathrm{al}^{9}$ & $57, F$ & 1 & 3 & $\begin{array}{l}\text { Yes, RT + } \\
\text { SRT (17) }\end{array}$ & No & PR & $24 w k$ & No \\
\hline Hahn et al $\left.\right|^{3}$ & $\begin{array}{l}54-72, \\
M \text { and } F\end{array}$ & 2 & 1,2 & Concurrent & $\mathrm{N} / \mathrm{A}$ & SD, PR & $4-34 \mathrm{mo}$ & No \\
\hline Reardon et al ${ }^{10}$ & $\begin{array}{l}\text { Median 50; } \\
\text { M 43\%, } \\
\text { F 57\% }\end{array}$ & 4 & $\mathrm{NA}$ & $33 \%(N A)$ & $\begin{array}{l}\text { Yes } \\
\text { (10\% of patients) }\end{array}$ & SD & $24 \mathrm{mo}$ & Yes \\
\hline Chamberlain $^{7}$ & NS & 13 & $\mathrm{NA}$ & $\begin{array}{l}\text { Yes, RT + } \\
\text { SRT (> } 3 \text { mo) }\end{array}$ & No & SD & $12 \mathrm{mo}$ & Yes \\
\hline
\end{tabular}

Abbreviations: ChemoRx, chemotherapy; mo pre-HU, therapy completed $x$ months before hydroxyurea administration; NA, not applicable; NOS, number of surgeries; NS, not specified; PR, progression; RT, radiotherapy; SD, stable disease.

radiologic regression after 5 months of $25 \mathrm{mg} / \mathrm{kg}$ of HU once daily, given within 1 month after stereotactic fractionated reirradiation. Although this is only a report of one patient, a plausible mechanism may be that $\mathrm{HU}$ sensitized the tumor to the previously administered ionizing radiation leading to tumor shrinkage and cavitation. Clearly, more research is needed to further explore this novel finding and further elucidate the potential of $\mathrm{HU}$ in treating anaplastic meningioma.

\section{References}

1 Modha A, Gutin PH. Diagnosis and treatment of atypical and anaplastic meningiomas: a review. Neurosurgery 2005;57(3): 538-550; discussion 538-550

2 Chamberlain MC. The role of chemotherapy and targeted therapy in the treatment of intracranial meningioma. Curr Opin Oncol 2012;24(6):666-671

3 Hahn BM, Schrell UM, Sauer R, Fahlbusch R, Ganslandt O, Grabenbauer GG. Prolonged oral hydroxyurea and concurrent 3D-conformal radiation in patients with progressive or recurrent meningioma: results of a pilot study. J Neurooncol 2005;74(2): 157-165

4 Newton HB. Hydroxyurea chemotherapy in the treatment of meningiomas. Neurosurg Focus 2007;23(4):E11

5 Brem SS, Bierman PJ, Brem H, et al; National Comprehensive Cancer Network. Central nervous system cancers. J Natl Compr Canc Netw 2011;9(4):352-400

6 Schrell UM, Rittig MG, Anders M, et al. Hydroxyurea for treatment of unresectable and recurrent meningiomas. I. Inhibition of primary human meningioma cells in culture and in meningioma transplants by induction of the apoptotic pathway. J Neurosurg 1997;86(5):845-852
7 Chamberlain MC. Hydroxyurea for recurrent surgery and radiation refractory high-grade meningioma. J Neurooncol 2012;107(2): 315-321

8 Schrell UM, Rittig MG, Anders M, et al. Hydroxyurea for treatment of unresectable and recurrent meningiomas. II. Decrease in the size of meningiomas in patients treated with hydroxyurea. J Neurosurg 1997;86(5):840-844

9 Mason WP, Gentili F, Macdonald DR, Hariharan S, Cruz CR, Abrey LE. Stabilization of disease progression by hydroxyurea in patients with recurrent or unresectable meningioma. J Neurosurg 2002; 97(2):341-346

10 Reardon DA, Norden AD, Desjardins A, et al. Phase II study of Gleevec ${ }^{\circledR}$ plus hydroxyurea (HU) in adults with progressive or recurrent meningioma. J Neurooncol 2012;106(2):409-415

11 Kubo O, Chernov M, Izawa M, et al. Malignant progression of benign brain tumors after gamma knife radiosurgery: is it really caused by irradiation? Minim Invasive Neurosurg 2005;48(6):334-339

12 Kunert P, Matyja E, Janowski M, Marchel A. Rapid growth of small, asymptomatic meningioma following radiosurgery. $\mathrm{Br} \mathrm{J}$ Neurosurg 2009;23(2):206-208

13 Kuroda H, Kashimura H, Ogasawara K, et al. Malignant intracranial meningioma with spinal metastasis-case report. Neurol Med Chir (Tokyo) 2009;49(6):258-261

14 Malik I, Rowe JG, Walton L, Radatz MW, Kemeny AA. The use of stereotactic radiosurgery in the management of meningiomas. $\mathrm{Br} \mathrm{J}$ Neurosurg 2005;19(1):13-20

15 Kuo ML, Kunugi KA, Lindstrom MJ, Kinsella TJ. The interaction of hydroxyurea and ionizing radiation in human cervical carcinoma cells. Cancer J Sci Am 1997;3(3):163-173

16 Kuo ML, Kinsella TJ. Expression of ribonucleotide reductase after ionizing radiation in human cervical carcinoma cells. Cancer Res 1998;58(10):2245-2252

17 Ward JF, Joner EI, Blakely WF. Effects of inhibitors of DNA strand break repair on HeLa cell radiosensitivity. Cancer Res 1984;44(1): 59-63 